\title{
Effect of Light Intensity and Light/Dark Period on Iridoids in Hedyotis diffusa
}

\author{
Kazuki Higashiuchi ${ }^{1}$, Yuichi UnO ${ }^{1}$, Shinichiro Kuroki ${ }^{1}$, Masaki Hisano ${ }^{1}$, Tomoka Mori ${ }^{2}$, \\ Chun Wai $\mathrm{WONG}^{3}$, Ping Chung Leung ${ }^{3}$, Clara Bik-San $\mathrm{LAU}^{3}$ and Hiromichi $\mathrm{ITOH}^{1}$ \\ Graduate School of Agricultural Science, Kobe University, 1-1 Rokkodai-cho, Nada-Ku, Kobe, Hyogo 657-8501, Japan \\ ${ }^{2}$ Faculty of Agriculture, Kobe University, 1-1 Rokkodai-cho, Nada-Ku, Kobe, Hyogo 657-8501, Japan \\ ${ }^{3}$ Institute of Chinese Medicine and State Key Laboratory of Phytochemistry and Plant Resources in West China, \\ The Chinese University of Hong Kong, Shatin, New Territories, Hong Kong
}

(Received December 28, 2015; Accepted February 29, 2016)

\begin{abstract}
The purpose of this study was to clarify the effects of light intensity and light/dark period on the concentration of iridoids in the plant Hedyotis diffusa, which finds use in herbal medicine. To investigate the effect of light conditions, plants were grown in a chamber with factorial treatments comprising three light/dark periods (14/10 h, 19/5 h and 24/0 h) and two light intensities (photosynthetic photon flux density of 142 and $40 \mu \mathrm{mol} \mathrm{m}^{-2} \mathrm{~s}^{-1}$ ). The epigeous dry weight was greatest with the treatments using high light intensity regardless of light period. The concentration of asperuloside (an iridoid) at $24 / 0 \mathrm{~h}$ was noticeably greater than that at $14 / 10 \mathrm{~h}$ or $19 / 5 \mathrm{~h}$ irrespective of light intensity. It was expected that the critical light period for the production of asperuloside would occur between $19 \mathrm{~h}$ and $24 \mathrm{~h}$. The content of asperuloside was greatest at 24/0 h under high light intensity. Therefore, high light intensity and a 24/0-h light/dark period can produce high-quality $H$. diffusa.
\end{abstract}

Keywords : asperuloside, environmental control, Hedyotis diffusa, iridoid glycoside, lighting condition, plant factory

\section{INTRODUCTION}

Medicinal plants are used as ingredients for crude drugs and herbal medicines. These medicines are traded at inflated prices for traditional primary medical care worldwide; demand for these preparations is increasing and exist throughout the year. In addition, as these plants are used for medicinal purposes, a high-quality and safe product is required. However, most medicinal plants are only available in the wild because methods for their cultivation have not been established. Therefore, it is difficult to provide high-quality and safe medicinal plants throughout the year. In Japan, medicinal plants are imported from foreign countries, with China being a major supplier (Japan Kampo Medicine Manufacturers Association, Crude Drug Commission, 2010). With the increasing demand in Japan for the production of high-quality medicinal plants, methods to cultivate the plants must be developed.

A plant factory is a year-round production system that produces a high-quality, safe and steady supply of vegetables using technological environmental controls and automation. However, such systems for the production of plants are costly and consume considerable energy, which hamper their profitability. This limitation might be resolved by cultivating high-value crops that contain useful substances in higher quantities than those present in crops cultivated in open fields.

Hedyotis diffusa (family Rubiaceae) is used in Chinese herbal medicine for treating cancer, urinary infection, ap- pendicitis and bronchitis. This plant's natural distribution is in eastern Asia in subtropical and tropical zones. The availability of $H$. diffusa depends on harvests of wild crops. A problem encountered in China during harvesting of $H$. diffusa is contamination with other similar cultivars because it is grown with other plants and weeds (Lin et al., 1987; Wee and Keng, 1990). Such contamination, which degrades the quality of herbal medicine, could be avoided if the plant were to be cultivated in a plant factory. The environmental control technology in a plant factory would produce a better quality product than that produced in the open field. However, to date, no cultivation system for $H$. diffusa has been clarified.

Iridoids are an active component in aerial part of $H$. diffusa, existing as iridoid glycosides. H. diffusa contains various iridoid glycosides, each one of which has been shown to exhibit different medicinal effects (Niu and Meng, 2013). In particular, numerous iridoid glycosides having an anti-oxidative activity have been reported ( $\mathrm{Lu}$ et al., 2000; Kim et al., 2005). It is considered that iridoid glycosides exist in the vacuole or cytoplasm of plant cell (Kamata, 2009). Figure 1 shows the biosynthetic pathway of iridoid glycosides (The Pharmaceutical Society of Japan, 2005; Shioi et al., 2009; Takaishi et al., 2010). The biosynthesis of iridoid glycosides begins with glucose and a promotion of photosynthesis increases the starting material of iridoid glycoside. In addition, biosynthesis of medicinal properties could be enhanced by environmental stimulation to induce protective response of plants (Kozai, 2012). It was commonly reported that a content of anti-oxidant has

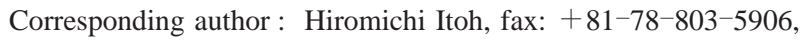
e-mail : hitoh@kobe-u.ac.jp 


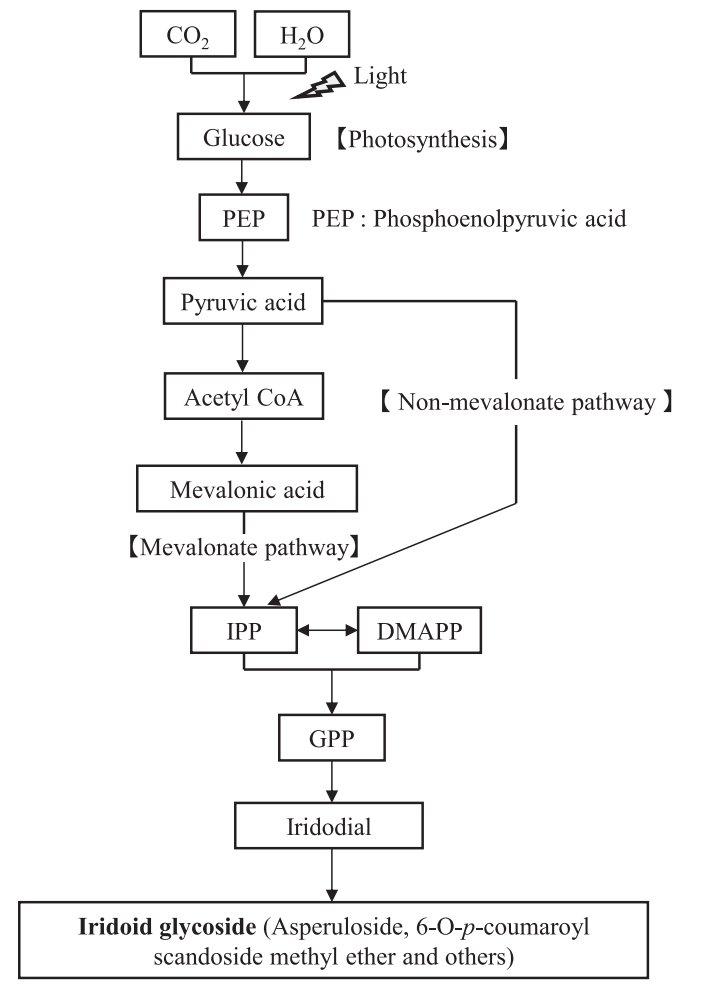

IPP : Isopentenyl diphosphate

DMAPP : Dimethylallyl diphosphate

GPP : Geranyl diphosphate

Fig. 1 Synthesis pathway of iridoid glycosides.

a strong correlation with day length (Hata et al., 2012). Therefore it is expected that the production of iridoids is affected considerably by day length and light intensity. Recently, an environmentally controlled method for rapid and high-quality production of $H$. diffusa was investigated. In particular, the effects of light/dark period and light intensity on plant growth and iridoid concentration were evaluated. Four different light/dark period treatments $(9 / 15 \mathrm{~h}$, $14 / 10 \mathrm{~h}, 19 / 5 \mathrm{~h}$ and $24 / 0 \mathrm{~h}$ ) were used, and for each of these, two different light intensity treatments were used (photosynthetic photon flux density $160 \mu \mathrm{mol} \mathrm{m} \mathrm{m}^{-2} \mathrm{~s}^{-1}$ and $50 \mu \mathrm{mol} \mathrm{m} \mathrm{m}^{-2} \mathrm{~s}^{-1}$ ) for a total of eight treatments. Results of our previous study (Higashiuchi et al., 2014) suggested that the increase in light period or light intensity promotes plant growth and production of photosynthetic products. $H$. diffusa grew up normally even under short day length with the small photosynthetic photon flux density of $50 \mu \mathrm{mol}$ $\mathrm{m}^{-2} \mathrm{~s}^{-1}$; many withered leaves and decrease in dry weight were observed under continuous light with $160 \mu \mathrm{mol} \mathrm{m} \mathrm{m}^{-2}$ $\mathrm{s}^{-1}$ photosynthetic photon flux density. H. diffusa showed prostrate type and could grow under small photosynthetic photon flux density. In addition, two kinds of iridoid glycosides were detected in $H$. diffusa: asperuloside and 6-O$p$-coumaroyl scandoside methyl ether. Asperuloside has anti-cancer effects, anti-oxidant effects and anti-angiogenic activity (Kapadia et al., 1996; Lu et al., 2000; Liang et al., 2008). Because of anti-cancer effects of asperuloside, it has higher value as a medicinal properties than 6-O- $p$ coumaroyl scandoside methyl ether which has anti-oxidant effects ( $\mathrm{Lu}$ et al., 2000). The concentrations of these components were enhanced by the increase in light intensity. However, the effect of the light/dark period differed for each iridoid glycoside. Concentrations of asperuloside increased with increasing light period, whereas those of 6-O$p$-coumaroyl scandoside methyl ether decreased. It would be difficult to increase the content of all iridoid glycosides by specific environmental conditions. Therefore, we selected asperuloside to limit the scope of quality evaluation conducted in this study. Although only relative concentrations were measured in our previous study (Higashiuchi et al., 2014), absolute concentrations for asperuloside were measured by another extracting method and quantitative analysis in the present study. In addition, the effects of light conditions on growth and absolute content for asperuloside were evaluated.

\section{MATERIALS AND METHODS}

\section{Raising seedlings}

In this study, raising the seedlings from scions rather than from seeds shortened the cultivation time by a maximum of $10 \mathrm{~d}$. Scions were harvested from the mother plants, which were hydroponically cultured for 6 weeks in closed chamber, i.e. former 2 weeks for raising the seedlings under $13 \mu \mathrm{mol} \mathrm{m} \mathrm{m}^{-2} \mathrm{~s}^{-1}$ photosynthetic photon flux density, $400 \mu \mathrm{mol} \mathrm{mol}{ }^{-1} \mathrm{CO}_{2}$ concentration and $70 \% \mathrm{RH}$ humidity at $14 / 10 \mathrm{~h}$ photoperiod and $25^{\circ} \mathrm{C}$ air temperature and latter 4 weeks for cultivation under $112 \mu \mathrm{mol} \mathrm{m} \mathrm{m}^{-2} \mathrm{~s}^{-1}$ photosynthetic photon flux density at $14 / 10 \mathrm{~h}$ photoperiod and $25^{\circ} \mathrm{C}$ air temperature to standardize the quality of scions. The seedlings for experimental treatments were grown from scions that were harvested from the mother plants. The seedlings were prepared as shown in Fig. 2. Each 45 $\mathrm{mm}$ scion was cut from the top of the mother plant. Four leaves with a midrib length longer than $10 \mathrm{~mm}$ were retained on the scion. The cut end of each scion was inserted at a $15 \mathrm{~mm}$ depth into a polyurethane foam cube $(23.5 \times$ $23.5 \times 30 \mathrm{~mm}$ ) and then placed in a transparent plastic tray (NF box \#7; Astage, Niigata, Japan). A $500 \mathrm{~mL}$ solution of half-strength Otsuka A prescription (OAT House No. 1 and No. 2; OAT Agrio, Tokyo, Japan) was added to 12 scions in the tray. After covering the trays with polyethylene film to suppress transpiration, they were placed in a growth chamber (NC200SC; Nippon Medical \& Chemical Instruments Co., Osaka, Japan). The 48 seedlings (12 seedlings $\times 4$ plastic trays) were grown for 2 weeks in the growth chamber under the conditions shown in Table 1 . The photosynthetic photon flux density was measured at the tray base using a quantum metre (Meter: Light Meter LI-250, Sensor: LI-190SA; LI-COR, Lincoln, NE, USA). The light was provided by fluorescent lamps (FL15EX-NHG, FL20EX-N-HG and GL40EX-N-HG; NEC Lighting, Tokyo, Japan). To suppress transpiration, the photon flux density was set below that used for cultivation. The solution was replaced once a week, and after 1 week, the polyethylene film was nicked by cutting with a knife to acclimatize the seedlings to a lower humidity. 


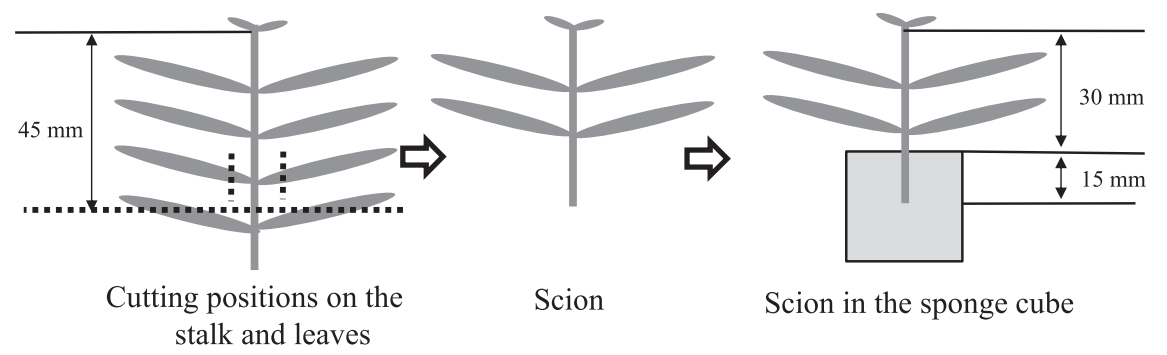

Fig. 2 Preparation of seedlings.

\section{Cultivation}

The 20 experimental seedlings were transplanted into the cultivation plate $(240 \times 360 \mathrm{~mm})$, which was floated onto the $10 \mathrm{~L}$ culture solution in the blue box (NF box \#13; Astage, Niigata, Japan) to suppress algae growth and then cultivated for 3 weeks in a growth chamber (BAC-130H; Especmic, Aichi, Japan). The culture solution was the same as that used for growing the seedlings. Air was pumped into the solution using an air pump (W-600; Nisso Industry, Osaka, Japan) and an air stone (LS-150A; Kainuma-sangyo, Aichi, Japan).

Three different light/dark period treatments $(14 / 10 \mathrm{~h}$, $19 / 5 \mathrm{~h}$ and $24 / 0 \mathrm{~h}$ ) were used, and for each of these, two different light intensity treatments were used (photosynthetic photon flux density $142 \mu \mathrm{mol} \mathrm{m} \mathrm{m}^{-2} \mathrm{~s}^{-1}$ and $40 \mu \mathrm{mol}$ $\mathrm{m}^{-2} \mathrm{~s}^{-1}$ ) for a total of six treatments. Photosynthetic photon flux density was decreased compared to previous study because of aged deterioration of fluorescent lamps. The growth chamber was divided into two parts, i.e. the upper for the high-intensity light treatments and the lower for the low-intensity light treatments. The inside glass wall of the lower space was covered with black cheesecloth to regulate the photon flux density. Table 2 presents the cultivation conditions. Earlier study demonstrated that drying stress and strong light stress produced by a rapid increase in light intensity and a sudden decrease in humidity during the transition from raising seedlings to transplantation led to poor growth and a reduced iridoid glycoside content (Hisano et al., 2013). Therefore, in the present study, the photon flux density and humidity were changed gradually to reduce the drying and light stresses. Twenty samples were cultivated for each treatment, and the solution was replaced once a week.

\section{Harvesting and drying}

The epigeous fresh weight was measured after harvest using an electric balance (GF-3000; A\&D Company, Tokyo, Japan). Owing to the risk of denaturation of the medicinal properties of plants by high-temperature drying, the samples were dried naturally at $25^{\circ} \mathrm{C}$ for $7 \mathrm{~d}$ after weighing. After drying, the epigeous dry weight was measured. Then, 20 samples were preserved at $-20^{\circ} \mathrm{C}$ in a freezer (KGT-4056HC; NIHON FREEZER, Tokyo, Japan) until component analysis.

Analysis of $H$. diffusa components

A sampling of $0.5 \mathrm{~g} H$. diffusa was repeated 4 times, and each samples contained 3 or 4 plants. Then, the asperuloside concentration was measured by liquid chromatography-mass spectroscopy (LC/MS). Therefore, for each

Table 1 Conditions for raising $H$. diffusa seedlings for experimental treatments.

\begin{tabular}{lll}
\hline Factor & Date $^{z}$ & Set value \\
\hline Light/dark period $(\mathrm{h} / \mathrm{h})$ & $1-14 \mathrm{~d}$ & $14 / 10$ \\
Air temperature $\left({ }^{\circ} \mathrm{C}\right)$ & $1-14 \mathrm{~d}$ & 25 \\
Relative humidity $(\%)$ & $1-14 \mathrm{~d}$ & 70 \\
Photosynthetic photon flux density $\left(\mu \mathrm{mol} \mathrm{m}^{-2} \mathrm{~s}^{-1}\right)$ & $1-14 \mathrm{~d}$ & $13 \pm 3.5$ \\
$\mathrm{CO}_{2}$ concentration $\left(\mu \mathrm{mol} \mathrm{m}{ }^{-2} \mathrm{~s}^{-1}\right)$ & $1-14 \mathrm{~d}$ & 400 \\
\hline
\end{tabular}

${ }^{2}$ Dates indicate days after transplanting.

${ }^{y}$ Mean \pm standard deviation measured at the bottom of the plastic tray.

Table 2 Conditions for the cultivation of $H$. diffusa.

\begin{tabular}{|c|c|c|}
\hline Factor & Date $^{2}$ & Set value \\
\hline Air temperature $\left({ }^{\circ} \mathrm{C}\right)$ & $1-21 \mathrm{~d}$ & 25 \\
\hline \multirow{2}{*}{ Relative humidity (\%) } & $1-7 \mathrm{~d}$ & 80 \\
\hline & $8-21 \mathrm{~d}$ & 70 \\
\hline \multirow{3}{*}{$\begin{array}{l}\text { Photosynthetic photon flux density }{ }^{y} \text { at high-intensity treatment } \\
\left(\mu \mathrm{mol} \mathrm{m} \mathrm{m}^{-2} \mathrm{~s}^{-1}\right)\end{array}$} & $1-4 \mathrm{~d}$ & $35.7 \pm 1.01$ \\
\hline & $5-7 \mathrm{~d}$ & $119 \pm 4.70$ \\
\hline & $8-21 \mathrm{~d}$ & $142 \pm 3.14$ \\
\hline \multirow{3}{*}{$\begin{array}{l}\text { Photosynthetic photon flux density }{ }^{y} \text { at low-intensity treatment } \\
\left(\mu \mathrm{mol} \mathrm{m} \mathrm{m}^{-2} \mathrm{~s}^{-1}\right)\end{array}$} & $1-4 \mathrm{~d}$ & $32.4 \pm 2.61$ \\
\hline & $5-7 \mathrm{~d}$ & $38.9 \pm 1.62$ \\
\hline & $8-21 \mathrm{~d}$ & $39.9 \pm 1.37$ \\
\hline $\mathrm{CO}_{2}$ concentration $\left(\mu \mathrm{mol} \mathrm{mol}{ }^{-1}\right)$ & $1-21 \mathrm{~d}$ & 400 \\
\hline
\end{tabular}




\section{K. HIGASHIUCHI ET AL.}

treatment, the sample number of asperuloside concentrations measured was four.

Deionized water was used for liquid extraction, and Milli-Q water was used for LC/MS. Methanol (LC/MS grade) was purchased from J. T. Baker (Pennsylvania, USA), and formic acid (LC/MS grade) was purchased from Sigma-Aldrich (Missouri, USA). Asperuloside was purchased from Standhill Technology (Hong Kong) and was used as a reference standard. The D101 macroporous adsorption resin was purchased from China.

Dried and powdered samples $(0.5 \mathrm{~g})$ of $H$. diffusa were extracted twice with $5 \mathrm{~mL}$ of deionized water under reflux; each extraction lasted $1 \mathrm{~h}$. After filtration of the aqueous fraction, the filtrate was concentrated to $2 \mathrm{~mL}$. The filtrate was concentrated to dryness by rotary evaporator (RE111; Buchi, Switzerland) and re-dissolved with 2 $\mathrm{mL}$ of deionized water. The concentrated extracts were then subjected to D101 macroporous adsorption resin and eluted with water and different concentrations of ethanol. Thirty-five percent ethanol fraction was concentrated to dryness under reduced pressure. The dried fraction was dissolved in $2 \mathrm{~mL}$ of water and filtered through a membrane filter $(0.22 \mu \mathrm{m})$ prior to analysis by highperformance liquid chromatography-electrospray ionization-mass spectroscopy (HPLC/ESI/MS).

HPLC measurements were performed using Agilent 1290 Infinity liquid chromatography (Agilent Technologies, USA), comprising an ultra-HPLC binary pump, an autosampler, a column oven and a diode array detector. Separation was performed on a C18 column (250 $\mathrm{mm}, 4.6 \mathrm{~mm}$ internal diameter, $5 \mu \mathrm{m}$; GRACE Alltima, USA), and the column temperature was set at $30^{\circ} \mathrm{C}$. The eluent system comprised A $[0.1 \%(\mathrm{v} / \mathrm{v})$ formic acid in aqueous phase] and $\mathrm{B}[0.1 \%(\mathrm{v} / \mathrm{v})$ formic acid in methanol] with a flow rate of $1.0 \mathrm{~mL} \mathrm{~min}{ }^{-1}$, which was performed with a linear gradient: $0^{-} 20 \mathrm{~min}, 7^{-} 15 \% \mathrm{~B} ; 20^{-} 30 \mathrm{~min}, 15^{-}$ $19 \% \mathrm{~B} ; 30^{-35} \mathrm{~min}, 19 \% \mathrm{~B}$ and $35^{-45} \mathrm{~min}, 19^{-95 \%} \mathrm{~B}$.

All MS experiments were conducted using a quadrupole time-of-flight mass spectrometer equipped with an ESI interface (Agilent Technologies, USA). Nitrogen was used as the drying gas with a flow rate of $12 \mathrm{~L} \mathrm{~min}^{-1}$. The drying gas temperature was set at $350^{\circ} \mathrm{C}$, and the nebulizer pressure was set at $60 \mathrm{psi}$. Spectra were recorded in positive ion mode at a spray voltage of $3500 \mathrm{~V}$. The mass scan range was between 50 and $1700 \mathrm{~m} / \mathrm{z}$.

Asperuloside content was calculated as a product of the average asperuloside concentration and epigeous dry weight.

\section{Statistical analysis}

Statistical tests were conducted using the nonparametric significant difference test. The Wilcoxon test method was adopted for comparison among 2 light intensity treatments, and the $\mathrm{S}$ method was adopted when multiple comparisons were performed for comparing among the 3 light/dark period treatments (Shirahata, 1987).

\section{RESULTS AND DISCUSSION}

Images of the harvested plants for each treatment are shown in Fig. 3. A spindly growth or color degradation was not observed at $14 / 10 \mathrm{~h}$ under low light intensity. Therefore, it was considered that $40 \mu \mathrm{mol} \mathrm{m}^{-2} \mathrm{~s}^{-1}$ photosynthetic photon flux density was larger than that of light compensation point for $H$. diffusa. The plants grown under high light intensity appeared to be larger than those grown under low light intensity. In contrast to previous research, no noticeable continuous light injury (chlorosis or necrosis) was observed under a continuous light treatment. Light injury results from the accumulation of radical oxygen. In addition, the degree of injury depends on the light intensity and the plant's anti-oxidative enzymatic activities (Hata et al., 2011; 2012). It was expected that radical oxygen beyond the capacity of anti-oxidative enzymatic activities of $H$. diffusa was not produced even under continuous light with $142 \mu \mathrm{mol} \mathrm{m} \mathrm{m}^{-2} \mathrm{~s}^{-1}$ photon flux density; moreover, no light-induced injury occurred.

Figure 4 shows the measurements of epigeous fresh weights, dry weights and percentage dry matter in the 6

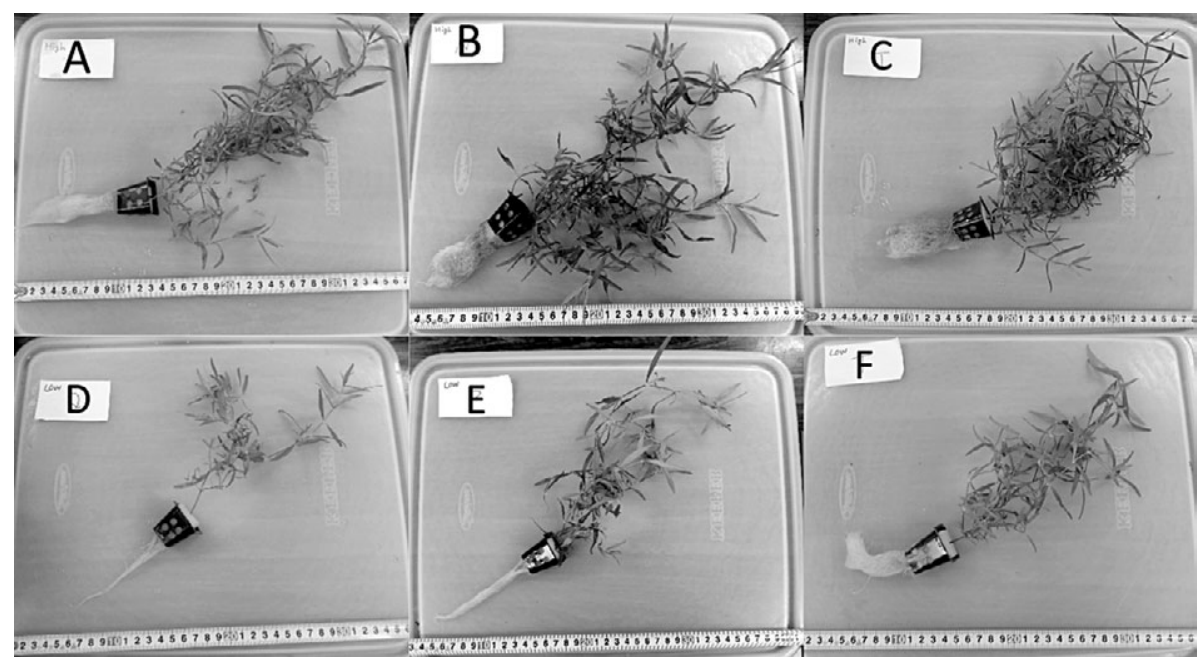

Fig. 3 Photographs of the harvested plants grown in 14/10 $\mathrm{h}$ in high-intensity light (A), 19/5 h in high-intensity light (B), 24/0 h in highintensity light (C), 14/10 h in low-intensity light (D), 19/5 h in low-intensity light (E) and $24 / 0 \mathrm{~h}$ in low-intensity light (F). 
light treatments. These measurements show a trend similar to the results obtained in a previous study (Higashiuchi et al., 2014). The mean epigeous fresh weights from the highand low-intensity light treatments in each light/dark period were significantly different at a $1 \%$ significance level. It seems that high light intensity promotes the growth of these plants. Among the light/dark periods, at high or low intensity, the epigeous fresh weights at $19 / 5 \mathrm{~h}$ and $24 / 0 \mathrm{~h}$ were greater than those at $14 / 10 \mathrm{~h}$. Therefore, the results suggest that a photoperiod of longer than $19 \mathrm{~h}$ is required to facilitate plant growth.

The mean epigeous dry weights and percentage dry matter from the high- and low-light intensity treatments in each light/dark period were significantly different at a $1 \%$ significance level. These results indicate the presence of more carbon assimilation products under high light intensity than those under low light intensity. Consequently, high light intensity promoted the photosynthetic rate of $H$. diffusa. When the dry weights of plants grown under three different light/dark periods were compared, the dry weight tended to increase as the light period increased. In general, under a long light period, feedback inhibition with starch accumulation or photoinhibition with radical oxygen elicits reduction in photosynthetic rate (Vermeglio et al., 1983; Teng et al., 2006). However, no light injury was observed
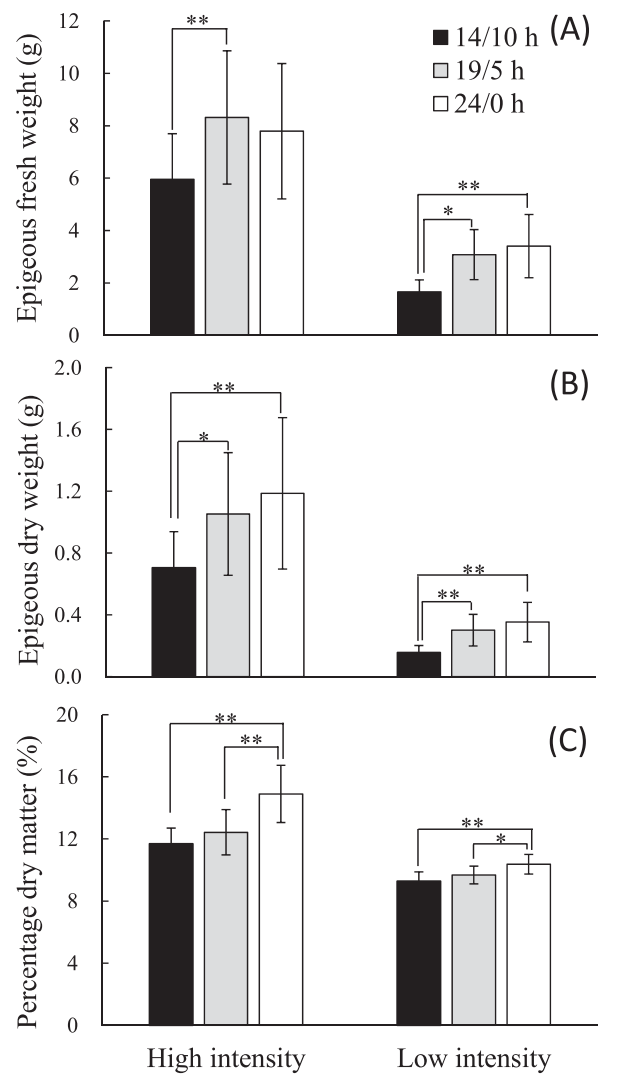

Fig. 4 Measurement of epigeous fresh weights (A), epigeous dry weight (B) and percentage dry matter (C). High intensity and low intensity indicate results of highintensity and low-intensity light treatments. $n=20$ for each experimental group. Bars indicate \pm standard deviation. Single asterisk $(P<0.05)$ and double asterisks $(P<0.01)$ indicate a significant difference between the two treatments (S method of multiple comparison). in this study. Therefore, it seemed that photosynthesis was not inhibited under the light condition. Because of the increase in the time capable of photosynthesis under a long light period, the amount of photosynthetic products produced in a day increased. Therefore, the long light period promoted the generation of photosynthetic products.

The mean percentage dry matter was markedly increased at $24 / 0 \mathrm{~h}$. It has been reported that continuous light can maintain transpiration of Metasequoia glyptostrobides and increase the water loss during $24 \mathrm{~h}$ (Yang et al., 2009). Therefore, it seemed that output of water augmented by continuous light led to the increase in percentage dry matter of $H$. diffusa in the $24 / 0 \mathrm{~h} \mathrm{light/dark} \mathrm{condition.}$

Figure 5 shows the relationship between the epigeous fresh weight or epigeous dry weight and accumulated photon flux density in a day. The accumulated photon flux density was calculated by multiplying the photoperiod by the photon flux density on or after the eighth day after transplantation. Epigeous fresh weight increased with the increase in accumulated photon flux density up to approximately $10 \mathrm{~mol} \mathrm{~m}^{-2} \mathrm{~d}^{-1}$ and decreased at approximately 12 mol $\mathrm{m}^{-2} \mathrm{~d}^{-1}$. Existence of peak value in the fresh weight was recognized. This relationship could be approximated by a quadratic function with a high value of coefficient of determination, and a maximum fresh weight at $10.5 \mathrm{~mol}$ $\mathrm{m}^{-2} \mathrm{~d}^{-1}$ was derived from the approximated curve. Epigeous dry weight linearly increased with the increase in accumulated photon flux density. It was inferred that the accumulated photon flux density that maximized the epigeous dry weight would be greater than the maximum
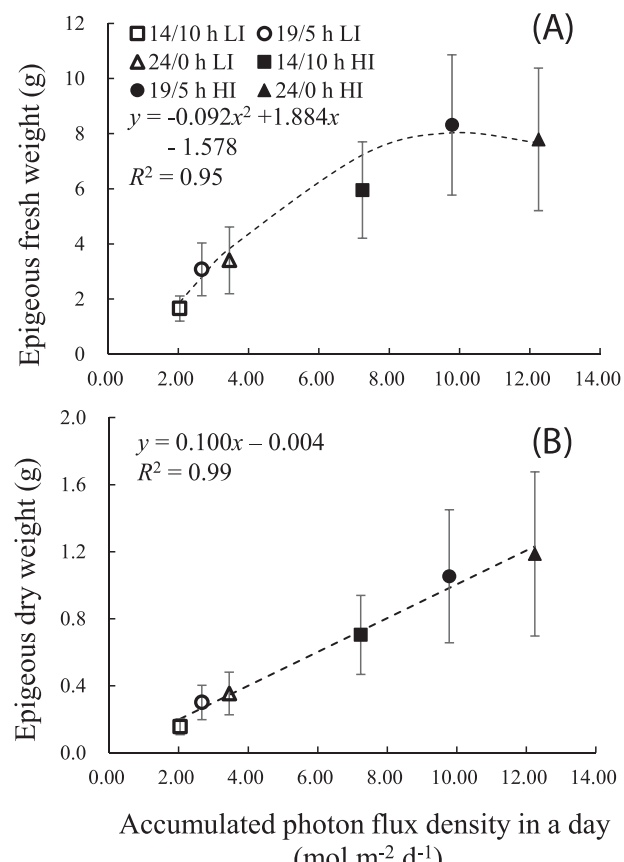

$\left(\mathrm{mol} \mathrm{m} \mathrm{m}^{-2} \mathrm{~d}^{-1}\right)$

Fig. 5 Relationship between epigeous fresh weight (A) or epigeous dry weight (B) and accumulated photon flux density in a day. $n=20$ for each experimental group. Bars indicate \pm standard deviation. The fitted curve (A) or regression line (B) and coefficients of determination $\left(R^{2}\right)$ were generated by quadratic or linear regression. HI, high intensity; LI, low intensity. 

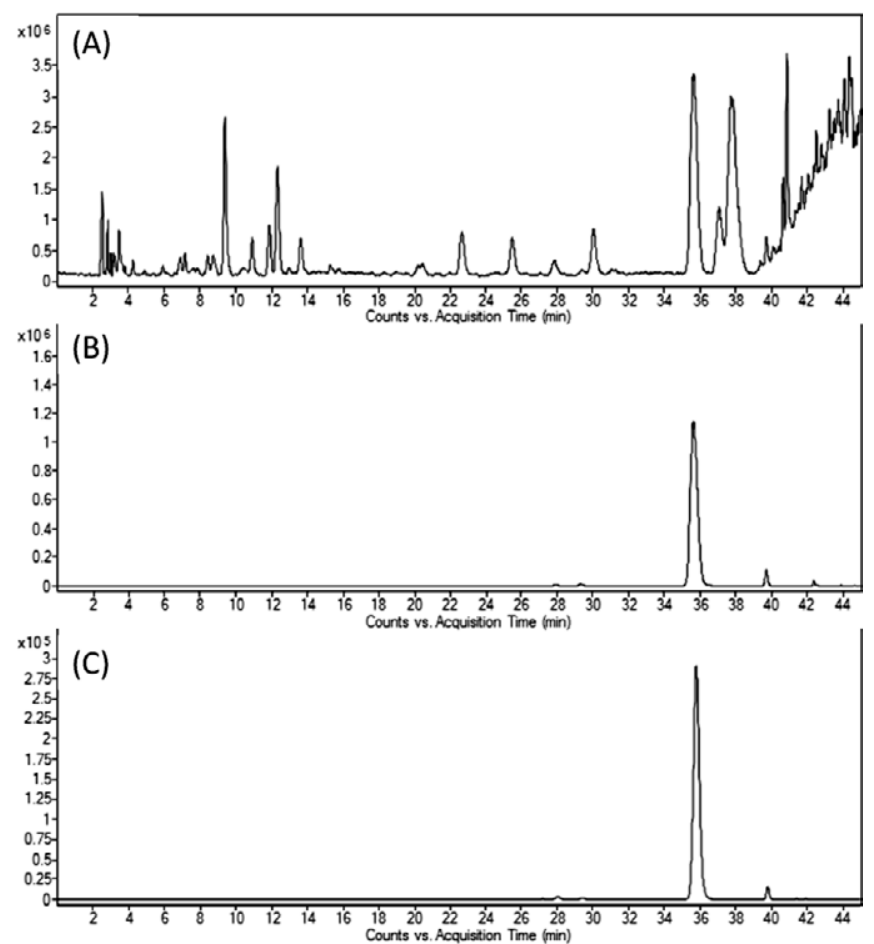

Fig. 6 Chromatograms of a sample. Total ion chromatogram (TIC) of Hedyotis diffusa (A); $437 \mathrm{~m} / \mathrm{z}$ extracted ion current (EIC) of $H$. diffusa (B); $437 \mathrm{~m} / \mathrm{z}$ EIC of the asperuloside standard compound (C).

value obtained in this study.

Figure 6 shows a chromatogram from one of the samples (Fig. 6A) and the asperuloside reference standard (Fig. 6C). The concentrations of asperuloside in $H$. diffusa were simultaneously quantified by a validated method. A calibration curve (ranging from $3.125 \mu \mathrm{g} \mathrm{mL}^{-1}$ to $100 \mu \mathrm{g} \mathrm{mL}^{-1}$ with $[\mathrm{M}+\mathrm{Na}]^{+}$at $437 \mathrm{~m} / \mathrm{z}$ ) with a good determination coefficient $\left(R^{2}>0.998\right)$ was constructed using MS peak areas of the reference standards versus their concentrations (Fig. $6 \mathrm{~B}$ and $\mathrm{C}$ ). The intra- and inter-batch precision was satisfied with a relative standard deviation of $<7.8 \%$ and an accuracy of $98.7-108.5 \%$.

Figure 7 presents the mean asperuloside concentrations on the basis of dry weights and asperuloside contents of $H$. diffusa. The mean asperuloside concentration was significantly greater under high light intensity than that under low light intensity with respect to each light/dark period at a 5\% significance level. Higher dry weights and higher concentrations of asperuloside were obtained from the condition of high light intensity. In other species, an increase in the secondary metabolite concentration associated with increasing photosynthetic photon flux density was reported (Mosaleeyanon et al., 2005). It seems that high light intensity promoted photosynthesis of $H$. diffusa, which produced glucose used for biosynthesis of secondary metabolites. In addition, high intensity light would enhance biosynthesis of the asperuloside. Therefore, the asperuloside concentration increased under high light intensity treatments. As for the comparison among the light/ dark periods, the asperuloside concentration at $24 / 0 \mathrm{~h}$ was noticeably higher than that at $14 / 10 \mathrm{~h}$ or $19 / 5 \mathrm{~h}$. Figure 8 shows the relationships among asperuloside concentration (Fig. 8A), asperuloside content (Fig. 8B), asperuloside

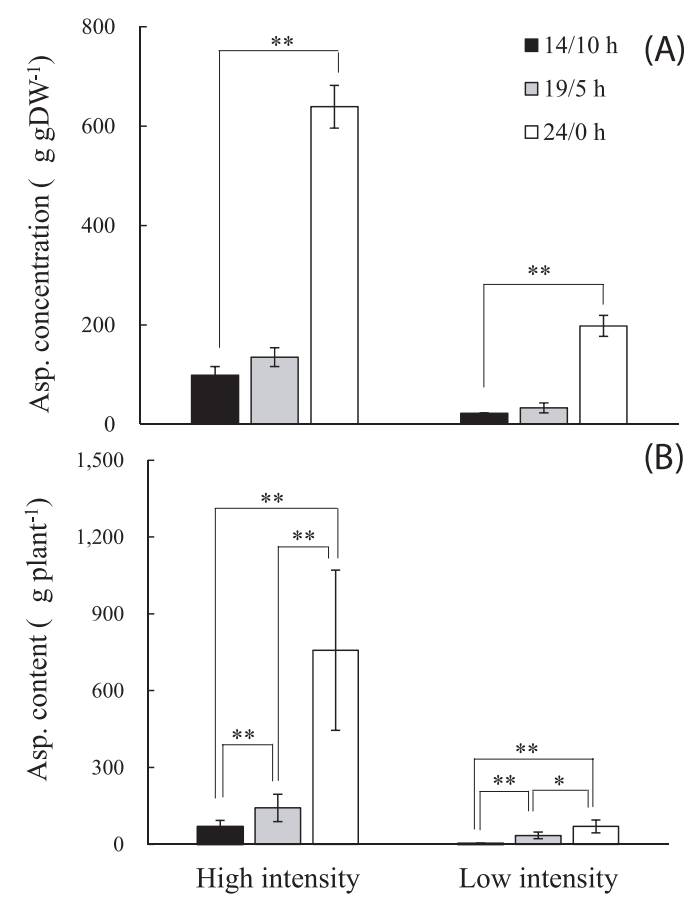

Fig. 7 Asperuloside (Asp.) concentrations (A) and asperuloside contents (B). High intensity and low intensity indicate results of high-intensity and low-intensity treatments. (A) $n=4$ and (B) $n=20$. Bars indicate \pm standard deviation. An asterisk $(P<0.05)$ and double asterisks $(P<0.01)$ indicate a significant difference between the two treatments (S method of multiple comparison). 
Hedyotis QUALITY CONTROL
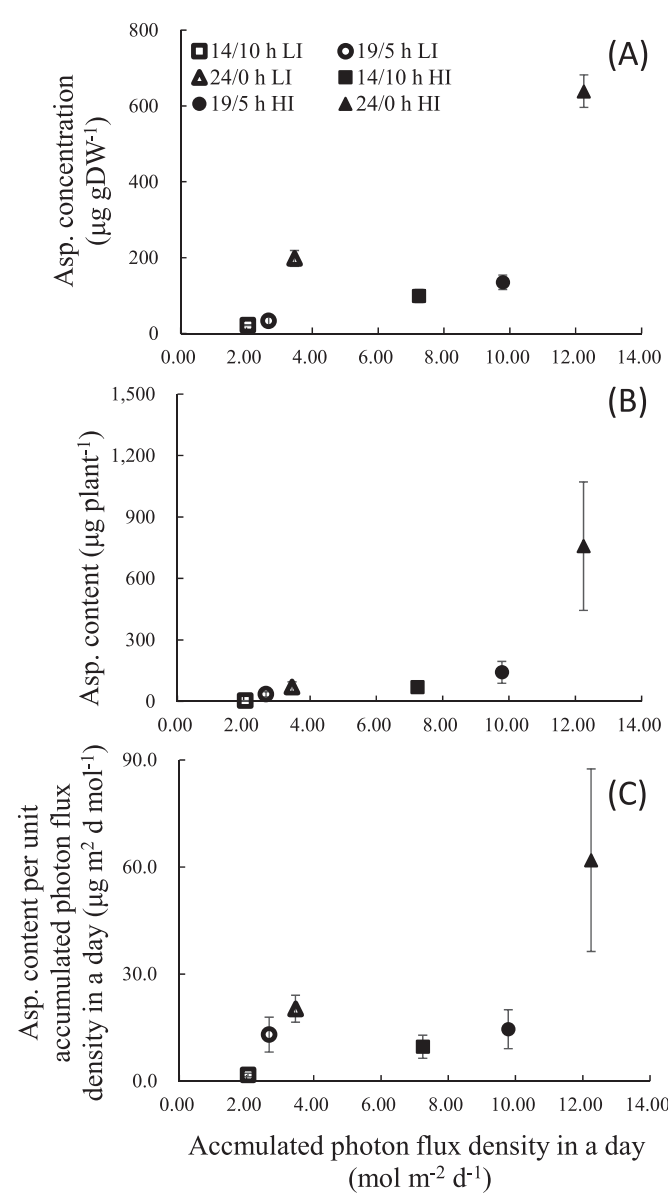

Fig. 8 Relationship between asperuloside (Asp.) concentration (A), asperuloside content (B) or asperuloside content per unit accumulated photon flux density (C) and accumulated photon flux density in a day. (A) $n=4$; (B and C) $n=20$. Bars indicate \pm standard deviation. HI, high intensity; LI, low intensity.

content per accumulated photon flux density (Fig. 8C) and accumulated photon flux density in a day. The accumulated photon flux density at $14 / 10 \mathrm{~h}$ under high light intensity was larger than that at $24 / 0 \mathrm{~h}$ under low light intensity. In contrast, the asperuloside concentration was significantly increased at $24 / 0 \mathrm{~h}$ under low light intensity compared with that at $14 / 10 \mathrm{~h}$ under high light intensity (Fig. 8A); therefore, it was thought that biosynthesis of asperuloside was profoundly affected by light period rather than accumulated photon flux density. It was expected that the threshold of light period for the production of asperuloside may exist between 19 and $24 \mathrm{~h}$. Increases in anti-oxidant concentration in sweet potato and Japanese mint with a prolonged light period have been reported (Carvalho et al., 2010; Malayeri et al., 2010). In addition, these behaviours could be associated with accumulation of radical oxidant. A decrease in moisture in $H$. diffusa at $24 / 0 \mathrm{~h}$ was found. The water deficit becomes a factor promoting the production of radical oxygen (Nicholas, 1993). It can be speculated that one of the reason of the significant increase in asperuloside concentration at $24 / 0 \mathrm{~h}$ could be partly attributed to the plant's protective response to the accumulation of radical oxidant elicited by continuous light.

Asperuloside content increased exponentially with the increase in accumulated photon flux density (Fig. 8B). High light intensity and a 24/0 h light/dark photoperiod were able to maximise the epigeous dry weight and asperuloside concentration; therefore, the content of asperuloside was the greatest at $24 / 0 \mathrm{~h}$ under high light intensity. In addition, the efficiency of asperuloside production per unit accumulated photon flux density in a day was highest at 24/0 $\mathrm{h}$ under high light intensity (Fig. 8C). Therefore, the increase in dry weight and the promotion of asperuloside biosynthesis are both necessary for efficient production of a high asperuloside content in Hedyotis diffusa. Consequently, high light intensity treatment $\left(142 \mu \mathrm{mol} \mathrm{m} \mathrm{m}^{-2} \mathrm{~s}^{-1}\right)$ and a $24 / 0 \mathrm{~h}$ light/dark photoperiod could promote high concentration of asperuloside and yield of $H$. diffusa.

\section{CONCLUSION}

High light intensity treatment $\left(142 \mu \mathrm{mol} \mathrm{m} \mathrm{m}^{-2} \mathrm{~s}^{-1}\right)$ and 24/0 $\mathrm{h}$ light/dark photoperiod successfully maximised the content of asperuloside because these light conditions induced both high epigeous dry weight and asperuloside concentration. In some cases, a suitable condition for the biosynthesis of secondary metabolites is not suitable for plant growth. However, in the case of $H$. diffusa, an optimal lighting condition, which can promote both growth and biosynthesis of asperuloside was specified. It seems that in $H$. diffusa, the production of anti-oxidants, including asperuloside, are affected profoundly by light period. The control of photoperiod is useful for an increase in concentration of medicinal properties. In addition, cultivation under an optimum accumulated photon flux density can obtain the highest yield of dry matter. The lighting conditions optimised both light period and accumulated photon flux density, making it possible to maximise efficiently the content of medicinal properties in plants. The results of this study could improve the profitability of plant factories producing $H$. diffusa.

\section{REFERENCES}

Carvalho, I. S., Cavaco, T., Carvalho, L. M., Duque, P. 2010. Effect of photoperiod on flavonoid pathway activity in sweet potato (Ipomoea batatas (L.) Lam.) leaves. Food Chem. 118: 384-390.

Hata, N., Masuda, M., Kobayashi, A., Muranaka, T., Okazawa, A., Murakami, K. 2011. Application of continuous light in a plant factory system 3 . Moderation of injuries induced by continuous light and relative tolerance to continuous light. (in Japanese) J. Sci. High Technol. Agric. 23: 137-143.

Hata, N., Masuda, M., Murakami, K., Kobayashi, A. 2012. Application of continuous light in a plant factory system 4 . Physiological change and concept of injury induction in plant leaves under continuous light (in Japanese). Sci. Rep. Faculty Agric., Okayama Univ. 101: 49-64.

Higashiuchi, K., Hisano, M., Nakano, Y., Uno, Y., Kuroki, S., Ishiguro, K., Oku, H., Itoh, H. 2014. Development of environmental control method for production of high quality Hedyotis diffusa. The International Conference on Plant Factory 2014. November. Kyoto. Proc. of International Conference on Plant Factory 2014 (USB). 


\section{K. HIGASHIUCHI ET AL.}

Hisano, M., Uno, Y., Ogino, N., Kitaaki, H., Ishigro, K., Oku, H., Itoh, H. 2013. Development of environmental control method for rapid production of high quality Hedyotis diffusa. 2013 IFAC Bio-Robotics Conference, March, Osaka, Proc. 2013 IFAC Bio-Robotics Conference, (http://www.ifacpapersonline.net).

Japan Kampo Medicine Manufactures Association Crude Drug Commission. 2010. Investigation Report of Crude Drug Usages II. (in Japanese). Japan Kampo Medicine Manufactures Association. p 2-18.

Kamata, N. 2009. Plant defence against insect attacks (II). (in Japanese) Tree For. Health 13: 21-27.

Kapadia, G., Sharma, S., Tokuda, H., Nisino, H., Ueda, S. 1996. Inhibitory effect of iridoids on Epstein-Barr virus activation by a short-term in vitro assay for anti-tumor promoters. Cancer Lett. 102: 223-226.

Kim, D. H., Lee, H. J., Oh, Y. J., Kim, M. J., Kim, S. H., Jeong, T. S., Baek, N. 2005. Iridoid glycosides isolated from Oldenlandia diffusa inhibit LDL-oxidation. Arch. Pharmacal Res. 28: $1156^{-1160 .}$

Kozai, T. 2012. Plant Factory with Artificial Light. (in Japanese) Ohmsha, Tokyo, pp 208.

Liang, Z., He, M., Fong, W., Jiang, Z., Zhao, Z. 2008. A comparable chemical and pharmacological analysis of the traditional Chinese medical herbs Oldenlandia diffusa and $O$. corymbosa and a new valuation of their biological potential. Phytomedicine 15: 259-267.

Lin, C., Chen, J., Namba, T. 1987. Development of natural crude drug resources from Taiwan (V). Pharmacognostical studies on Chinese crude drug "Peh-hue-juwa-chi-chhau" (白花蛇舌草) (1). Shoyakugaku Zasshii 41: 180-188.

Lu, C., Yang, J., Wang, P., Lin, C. 2000. A new acylated alavonol glycoside and antioxident effects of Hedyotis diffusa. Planta Medica 66: 374-377.

Malayeri, S. H., Hikosaka, S., Goto, E. 2010. Effects of light period and light intensity on essencial oil composition of Japanese mint grown in a closed production system. Environ.
Control Biol. 48: 141-149.

Mosaleeyanon, K., Zobayed, S. M. A., Afreen, F., Kozai, T. 2005. Relationships between net photosynthetic rate and secondary metabolite contents in St. Jhon's wort. Plant Sci. 169: $523-531$.

Nicholas, S. 1993. Tansley review No. 52. The role of active oxygen in the response of plants to water deficit and desiccation. New Phytol. 125: 27-58.

Niu, Y., Meng, Q. 2013. Chemical and preclinical studies on Hedyotis diffusa with anticancer potential. J. Asian Nat. Prod. Res. 15: 550-565.

Shioi, Y., Inoue, H., Kondo, N. 2009. Basic Master Series Plant Physiology. (in Japanese) Ohmsha, Tokyo, p 249-254.

Shirahata, S. 1987. Personal Computer Statistical Analysis Handbook IV Non-Parametric Volume. (in Japanese) Kyoritsu Shuppan, Tokyo, p 1-173.

Takaishi, Y., Baba, K., Honda, G. 2010. Natural Products Chemistry Text. (in Japanese) Hirokawa Publishing, Tokyo, p 104-110.

Teng, N., Wang, J., Chen, T., Wu, X., Wang, Y., Lin J. 2006. Elevated $\mathrm{CO}_{2}$ induces physiological, biochemical and structural changes in leaves of Arabidopsis thaliana. New Phytol. 172: 92-103.

The Pharmaceutical Society of Japan. 2005. Chemical Pharmacy III. (in Japanese) Tokyo Kagaku Dojin, Tokyo, pp 72.

Vermeglio, A., Carrier, J. M. 1983. Photoinhibition by flash and continuous light of oxygen uptake by intact photosynthetic bacteria. Biochimica et Biophysica Acta 764: 234-238.

Wee, Y., Keng, H. 1990. An Illustrated Dictionary of Chinese Medicinal Herbs. Times editions, Singapore, pp 92.

Yang, H., Pagani, M., Briggs, D. E. G., Equiza, M. A., Jagels R., Leng, Q., LePage, B. A. 2009. Carbon and hydrogen isotope fractionation under continuous light: implications for paleoenvironmental interpretations of the high arctic during Paleogene warming. Oecologia 160: 461-470. 